Revista Criação\&Crítica n.4, abr/2010

- Qu'en penses - tre?

- Porrquor pas?

- Por quoi pas m'intrigue do jojuss, mais ee n'ect pas aresi genant que "quoi de kenf?"

- Quor d'étonnant me plaît.

- Ie n’ar jamais rien de venf à dire. Et pourtant je reponds.

- Counne un journal.

- Comme d'habitude...

que são, gruardados agora, os teus cadernos? 
Como escrever junto

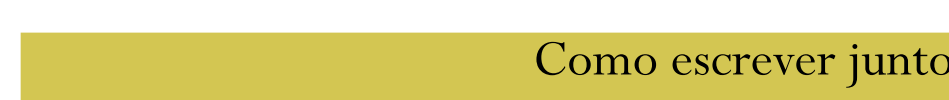

Artigo recebido em: 09/03/2010

Artigo aprovado em: 09/03/2010

Referência eletrônica: COELHO, Ana Amelia; TOMMASO, Mário, PESCE, Priscila. “O que são, guardados agora, os teus cadernos?”, Revista Criação \& Crítica (online), n. 4, pp.259-271, 2010. Disponível em:

http://www.fflch.usp.br/dlm/criacaoecritica/dmdocuments/21CC_N4_CoelhoPesceTommaso.pdf

\section{de alguém?}

do outro que fui?

dos objetos que me cercam?

das superfícies de inscrever?

das máquinas de escrever?

do corpo-máquina de escrever?

dos materiais que envelhecem?

da memória?

da vida cotidiana?

do imprevisto?

do improviso?

das contraintes?

do dicionário?

do leitor?

destas perguntas — pelas quai

nos deixamos seduzir e que

serviram de mote para inventar

um jogo de escrever... 
Numa caixa de sapatos estão 8. guardados os negativos de fotos que Ta não existem e queimadas. Abrir a caixa para o meu textos meus: um conto para da irmão, um soneto sobre a ch 1808, um família real portuguesa em 180 foram poema sobre a chuva. On falta? Seria parar? Por que me fazem falas restam porque das páginas perdidas restá porque das pouco dizem, porq pedaços que pouco memória? pebraram trechos na memoria?
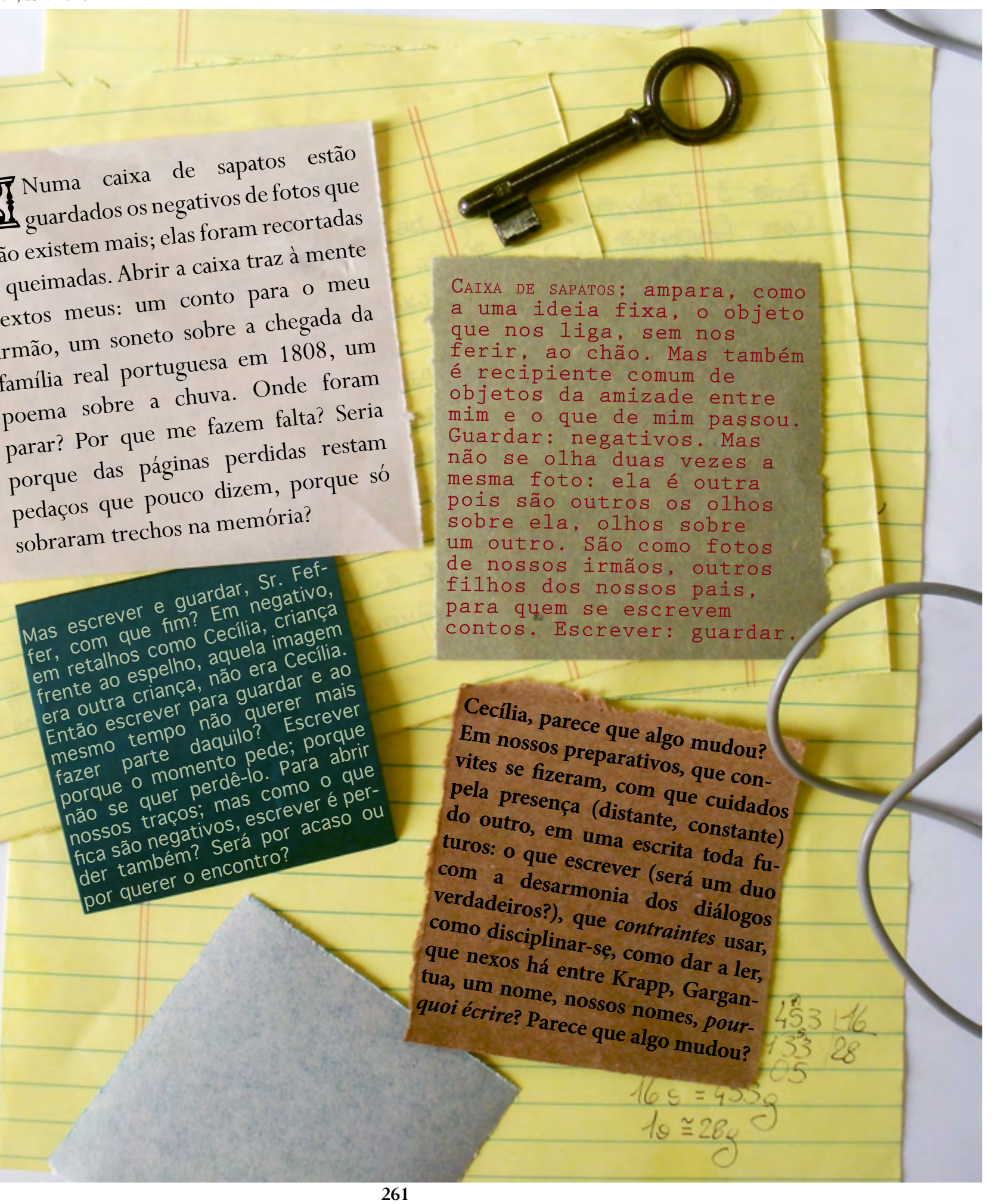

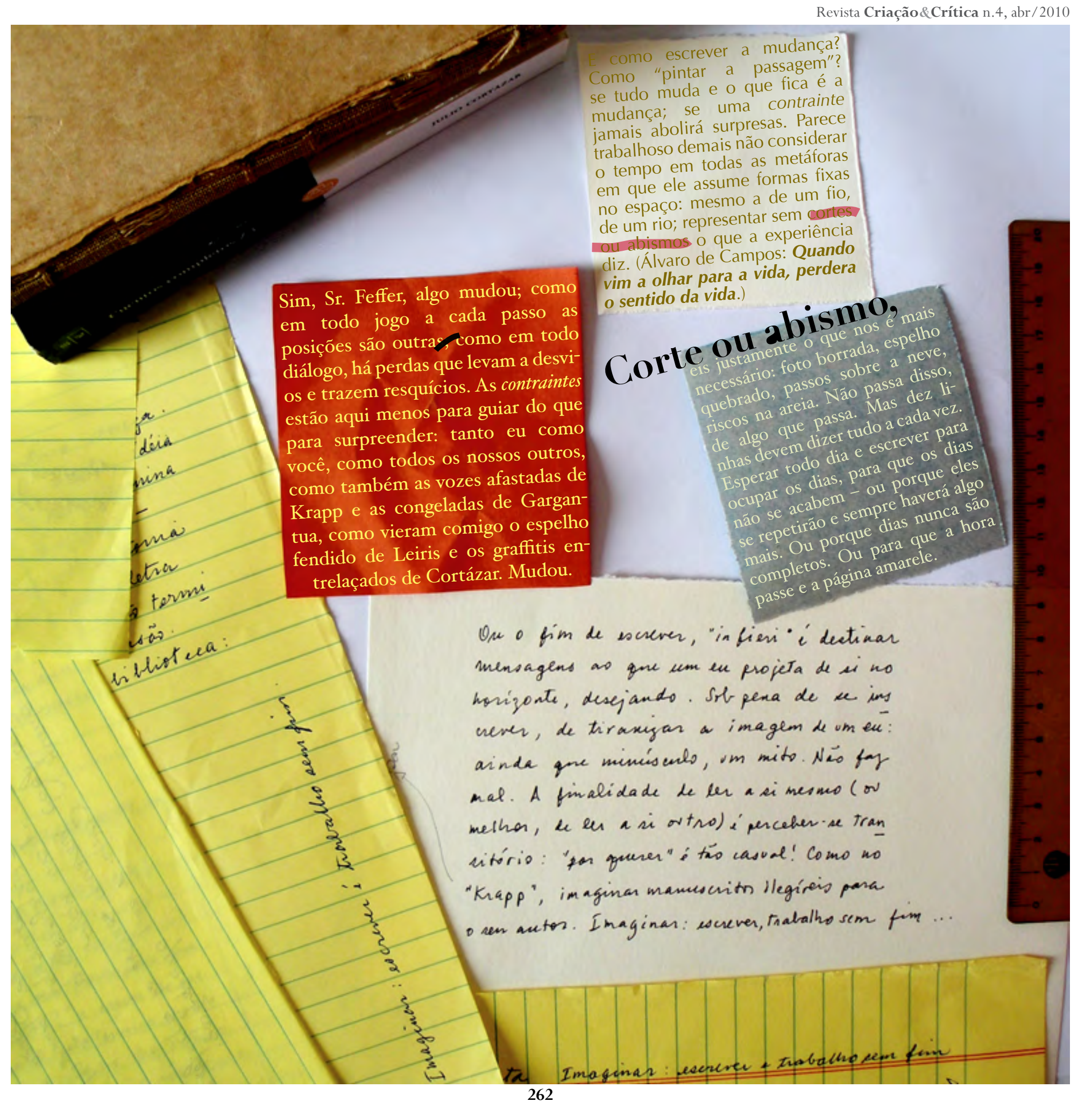




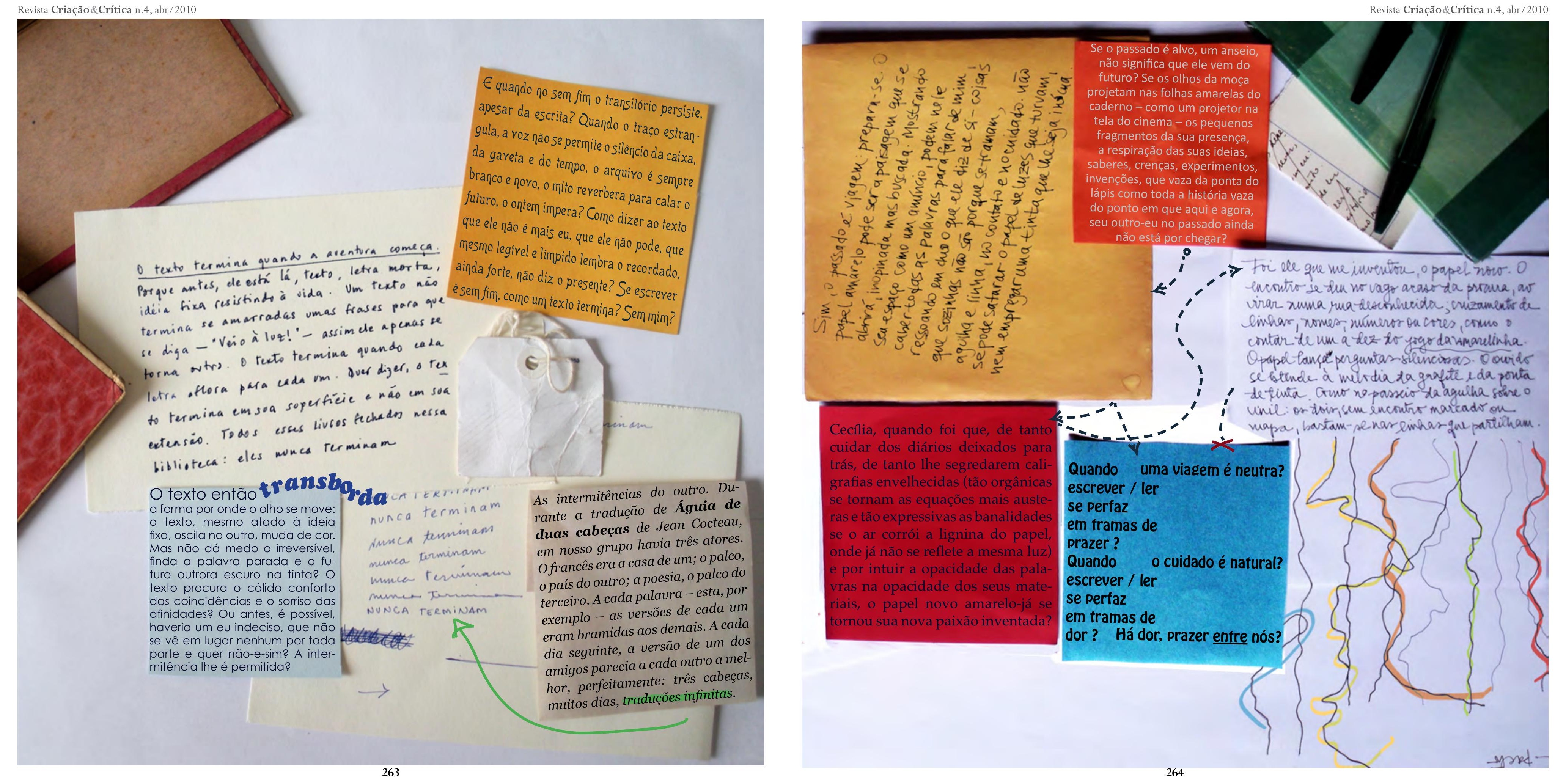




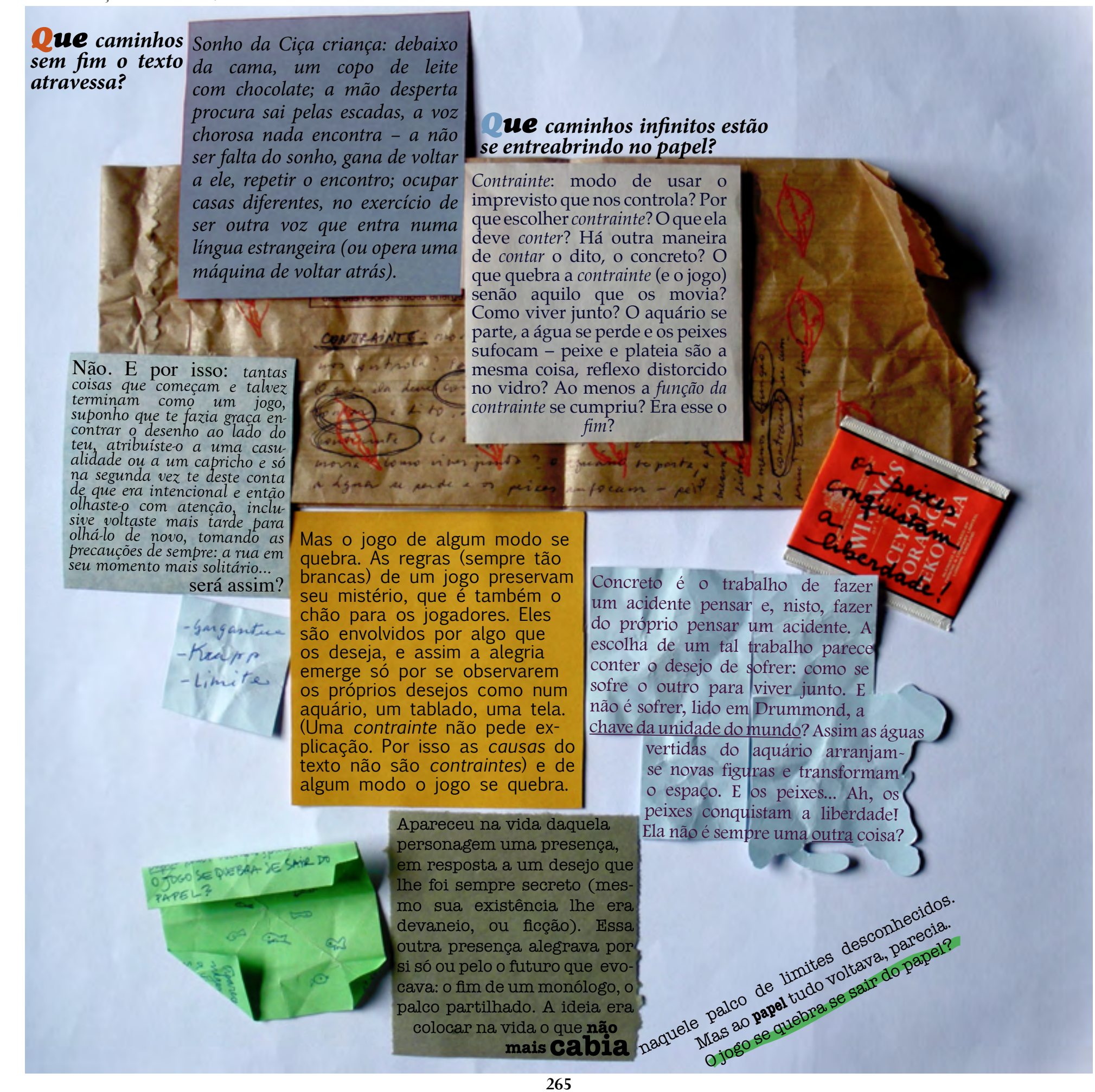




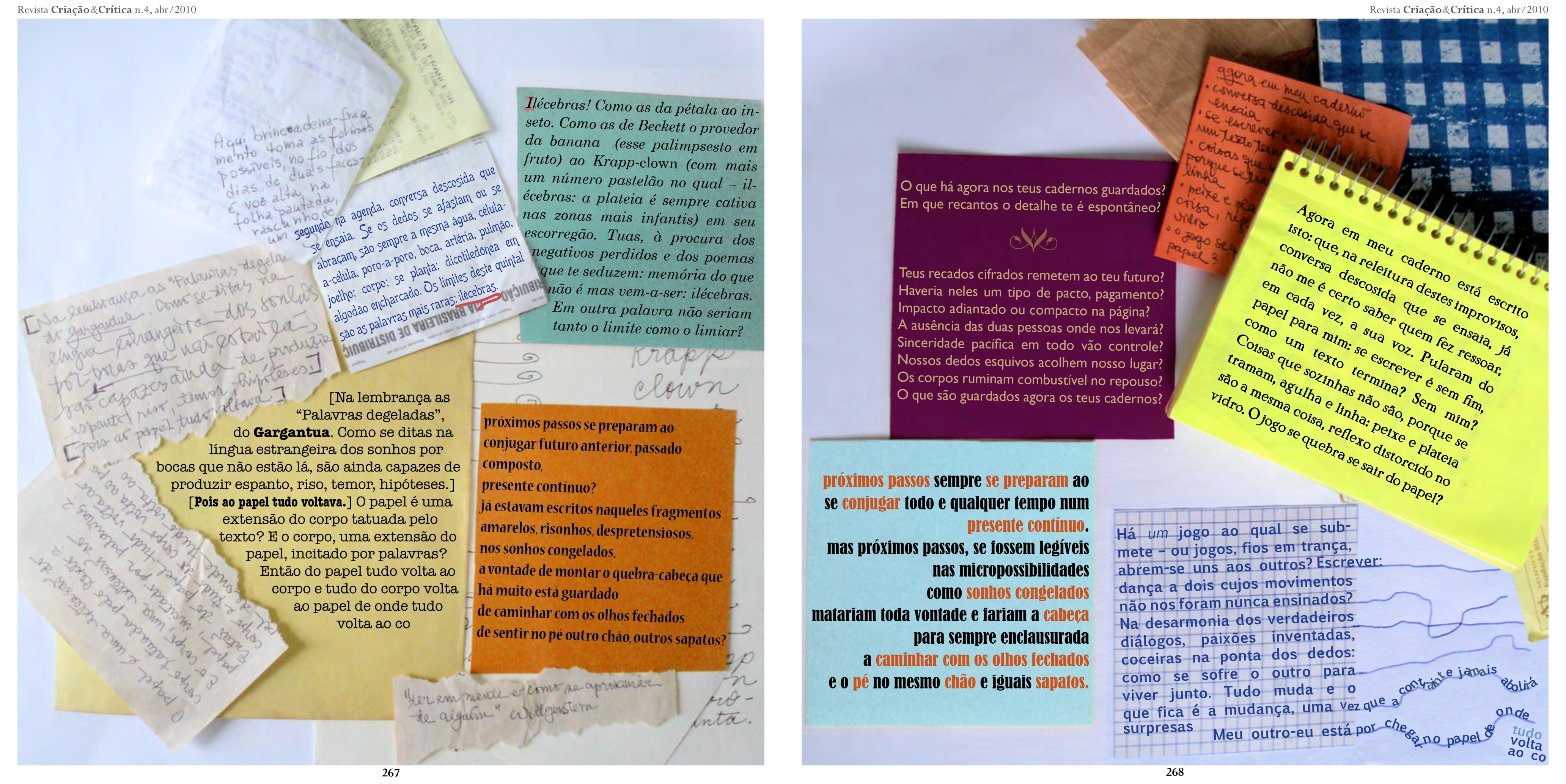




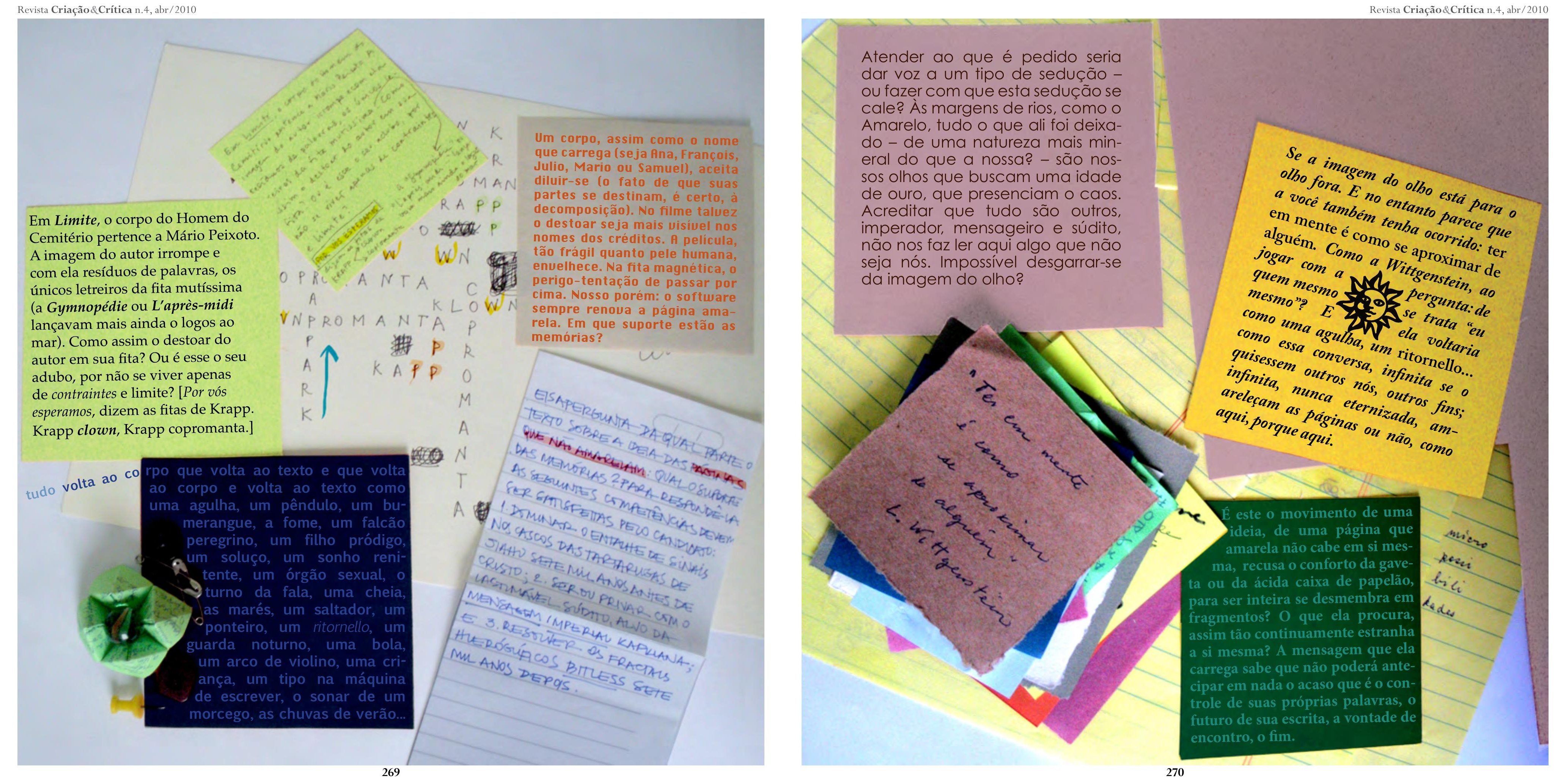


Convite aceito, pensamos que o texto poderia ser um duo: linhas melódicas que vão se cruzando, dois temas figurando dois "eus-outros". Ficaria na forma de um diálogo, não em uníssono (como seria um texto de duas mãos querendo fingir ser de uma só).

Nessa entrevista de mão dupla, gostamos da ideia de haver contraintes, regras para controlar a extensão do texto e o ritmo de trabalho, e também para modular a escrita, como restrições gramaticais.

Começamos simultaneamente dois diálogos, por e-mail, em 10 de janeiro de 2010: nos dias pares, "perguntas" e nos ímpares, "res-

postas". Durante esses rounds, uma interdição: que não conversássemos fora do texto, nem pessoalmente nem por e-mail, e que toda dúvida se resolvesse dentro da escrita ou depois dela. Em vinte dias, tínhamos 40 turnos de 10 linhas e uma nova questão: como dar a ler? Já tínhamos escrito o texto a dois, já éramos outros e aquele “nós” já havia se tornado um outro. O texto operava as inquietações que o motivaram.

Nossa conversa, agora, já tinha se apartado do começo. Devíamos nos permitir alterar um o texto do outro? Como, se já confundíamos os sujeitos de cada fala? A quem essas vozes pertenciam? Às duas personagens. E como situá-las?
Foi então que uma terceira pessoa, desejada desde o princípio do trabalho, foi chamada a intervir.

A ideia de não conhecermos o Outro de nós se colocava como provocação.

Cogitamos de chamar alguém totalmente desconhecido, escolhido sob uma nova contrainte: um Samuel, como Beckett, ou um Julio, como Cortázar, encenaria uma feliz coincidência. Mesmo assim, hesitamos diante do imprevisível e nos deparamos com a vontade de preservar algum domínio sobre a expectativa do que esse leitor-autor poderia nos oferecer. Tal hesitação se estendia à própria con-

trainte, não levada às últimas consequências. $\mathrm{O}$ que é um risco para o jogo: jogá-lo até o fim (o jogo toma as rédeas e seja o que for) ou dar um fim ao jogo (os jogadores constrangem as contraintes)?

Contamos com certo acaso controlado: a contrainte cotidiana de ser escolhido pelos outros — quem vive junto.

E o outro outro (que era de fato uma outra) leu-escreveu, escrevendo sua leitura com contraintes (quadrados intercambiáveis mas indissolúveis), oferecendo aos olhos alheios a fragmentação do quotidiano desta escrita, querendo as rotas perecíveis aos sopros do próximo outro. 通 